\title{
Literality of Metaphor in Science Fiction
}

\author{
Gayane Muradyan \\ Yerevan State University
}

\begin{abstract}
$\mathrm{T}$ heoretical discussions on Science Fiction (SF) so far have articulated the urgent need to define this broad literary genre. But the fact is that SF hasn't had a neat, final definition so far. The common view is that a fixed definition may draw SF towards a mere limitation to formula. The general approach is to consider it an art dependent on intellect: speculative fiction, imaginary science, scientific romance, storytelling about future, technology of emotions, as named by SF writers and analysts. Art is specifically used to support the cognitive reflection in science, in a wider sense art and cognition are intimately associated. Therefore, science is the frame and the fantasy and visions of the author are the content of SF. Sometimes SF is proclaimed to be "the mythology of the modern world" (LeGuin 1993:21) and this approach can be well justified: although SF began to emerge with the development of science itself, as a means of understanding the world through speculation and storytelling, it really has antecedents back to mythology. SF commonly uses techniques both from the realistic and the fantastic traditions of narrative to tell a story of which a referent, implicit or explicit, is the mythos of modern world (described as a virtual world) and can educate the imagination beyond the constraints of mainstream mindsets. SF is also qualified as "a modern fairy tale". As in fairy tales and mythology the discourses of narration and description play an important role in it. And as in fairy tales and mythology the origin of the imagery, the motive of the narrative is to be found in the contents, assumptions and views of the present world. At this juncture, it should be stressed that the stylistic device of literalization of metaphor ${ }^{1}$ is realized exceptionally in fairy tales and SF. And like in fairly tales of all nations, Evil is always defeated here.

The following passage is a piece from the cyberpunk story by Paul Di Filippo "Stone Lives" published in "The Cyberpunk Anthology" (ed. Bruce Sterling. NY: Arbour House, 1986).
\end{abstract}

Following the current craze, she has had a subdermal pattern of microchannels implanted. The channels are filled with synthetic lucifirase, the biochemical responsible for the glow of fireflies, which she can trigger now at will. In the afterglow of lovemaking, she has set herself alight. (p.194)

The first sentence of the passage reminds the reader that no matter how normal things may appear in a piece of SF (Following the current craze, she has had a subdermal pattern of microchannels implanted), you can always expect some punk to pop into the scene with the lucifirase, a good example of a newly coined SF term. The verb trigger is used in a sense other than the expected metaphorical one as it is applied to turning on the glow of the body. The passage gradually becomes more effective: starts out normally grounded (implantations are quite common today), then becomes typically science fictional (with the heroine turning the lights of her body on at will) and reaches a climax 
exemplified in the stylistic device of literalization of metaphor which, as mentioned above is a typical characteristic of only SF and fairy tales and never occurs in realistic fiction. In realistic fictional context such metaphors can be described as "dead", in the sense that the reverse process of them to become literalized is impossible.

The metaphor she has set herself alight in other discourses of realistic fiction would be associated with passion but in the SF context, in addition to symbolizing love, it has been literalized, i.e. the heroine has in fact turned on the lucifirase matter filling her subdermal microchannels, in this way making her body luminous.

Literalized metaphors or literality of metaphor exemplify what I believe to be a significant stylistic marker for SF. As Ursula K. LeGuin notes "Literalization of metaphor is a characteristic of science fiction. In teaching the craft to people new to it, I use Delany's phrase 'subjunctive tension' to alert them to a challenge not present in realistic fiction: the way in which the open context of science fiction brings the language alive" (LeGuin 1993:30). We come across many examples of this tool in the story: Stone is a living camera (he can take pictures using his eyes), when he still retained his eyes (when the camera was still installed in him), don't take the eyes back (he didn't want the camera to be taken out), practicing his new eyes (using the eye camera), his eyes go dead (the camera was switched off). Through the highly important marker of literality of metaphor SF signals not only its stylistic uniqueness but the difference between the present and future as well.

We come across numerous cases of literalized metaphors in R. Zelazny's "Jack of Shadows" (Toronto: Fitzhenry and Whiteside, Ltd., 1971) where the mortal hero can die deaths and resurrect after each through gaining strength and flesh from shadows.

\author{
"Everyone knows that darksiders have more than one life. How many \\ have you?" \\ "It is not as if you would be dead forever." \\ "It is a long way back from the Dung Pits of Glyve at Western Pole of \\ the world, and one must walk. It sometimes takes years to constitute a new \\ body." (p.11)
}

And again after a long while he felt himselffalling - falling as from a great height, gaining a substance, until he realized that he was lying on his back staring upward with the full weight of his being once again on him. (p.14)

It was always with a certain sadness that he reflected on the loss of blood from any new body which also happened to be his own. (p.16)

Flocks of meteors constantly strung the sky, reminding him of the appearance of heavens on the day of his last resurrection. (p.133)

Interestingly enough we come across the same resurrection phenomenon (and respectively an extended literalized metaphor) in F.M. Busby's "If this is Winnetka, You Must be Judy" ("Best Science Fiction Stories" edited by Lester Del Ray. NY: ACE books, 1977). 
Having died, he still feared death. It would be merely a different way of ending. For he had no clear idea how much of his life had been lived, back and forth in bits and pieces. One day he would use up the last unlived segment, and then...he supposed he simply wouldn't wake up. At his best estimate he had lived something less than half his allotted timeyears. (p.19)

Making clear as to what literality of metaphor is, LeGuin brings the example "He was absorbed in the landscape." (LeGuin 1993:30) which in an ordinary story is a quite safe sentence to create the image of an artistic nature admiring the beautiful scenery, while in SF narrative the same phrase should be used very carefully as it may be depicting a piece of cannibal landscape devouring its victims or a scenery eating the characters. Interestingly enough in Roger Zelazny's "Jack of Shadows" we come across another such phenomenon, a monster stone, faintly glowing and pink which lay in the valley and is later slain by the protagonist who literally ate the stone instead of being eaten by it.

"I lie before you little one. Come to me".

"I see just a moldy rock".... He staggered as he beheld the heap of skeletons that were lying behind the glowing stone. "Yes. I must position them there so that newcomers to this place will not grow fearful and avoid the circle of my influence. It is there that you, too, will lie, bloody one”. (p.25)

I am Shadowjack, the thief who walks in silence and in shadows! I was beheaded in Igles and rose again from the Dung Pits of Glyve. I drank the blood of a vampire and ate a stone. I am the breaker of the Compact. I am he who forged a name in the Red book of ells. I am the prisoner in the Jewel. (p.85)

The mammoths seen by man, whales in Kurdistan, the angel who walked and stood in those high plains saying he was named Man, Mary Rainwood who gazed upon her own double and talked with her from R.A. Lafferty's "And Name my Name" ("Best Science Fiction Stories" edited by Lester Del Ray. NY: ACE books, 1977) are also good examples of literalized metaphors. Exemplifying an important stylistic marker for Science Fiction writing in general, the stylistic device of literalization of metaphor is still awaiting to be thoroughly investigated.

Science Fiction is developing and booming today as the penetration of science and new technology into society has created a deep interest in English literature exploring technologies which influence the global society. Today Anglo-American Science Fiction is represented in all varieties of advanced communication, words coined in science fiction have become part of the vocabulary of any number of subcultures and endeavors, from comics, to aerospace, to computers, to environmentalism, to zine culture, to poli- 
tics. SF has a significant impact upon the behavior of individuals in the society, world culture, thought, education and English language.

In conclusion it should be said that investigation of a discourse is part of the inflationary process by which genres survive, endure, propagate. Science Fiction with its panoply of luminous and vivid worlds, lies in all its potential to be explored by linguists.

\section{Notes:}

1. A good example of literalization of metaphor are the following word-combinations from fairy tales or SF: "red river", "silver/white sun" or "to speak to one's own soul". In a mundane narration they will probably depict metaphorically a bloody scene, cold, unfriendly sun or one's inner speculations with the self while in SF and a fairy tale the mundane metaphors acquire a literal meaning: the river is actually red-coloured, the sun - silver/white-coloured or made of silver and one can actually live separately from one's soul and even communicate with him/her.

\section{References:}

1. Delany, S.R. (1977) The Jewel-Hinged Jaw: Notes on the Language of Science Fiction. Elizabethtown, NY: Dragon Press.

2. Freedman, C.H. (2000) Critical Theory and Science Fiction. Middletown, Ct: Wesleyan University Press.

3. LeGuin, U.K and Attebery, B. (Ed.-s) (1993) The Norton Book of Science Fiction. W.W. New York: Norton and Company Inc.

4. Scholes, R. and Rabkin, E. (1977) Science Fiction: History-Science-Vision. Oxford, UK: Oxford University Press.

5. Wolfe, G.K. (1979) The Known and the Unknown. Kent, OH: Kent State University Press.

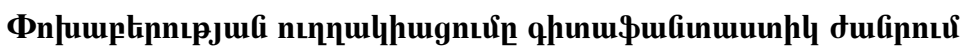

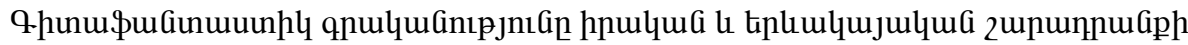

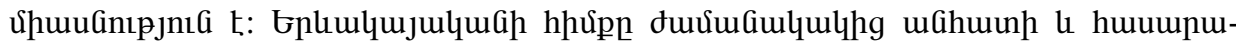

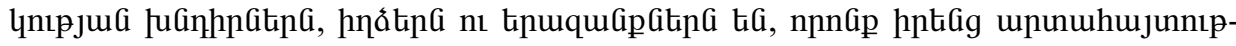

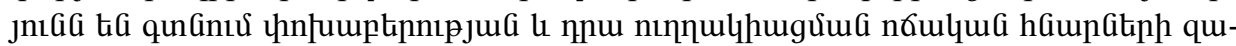

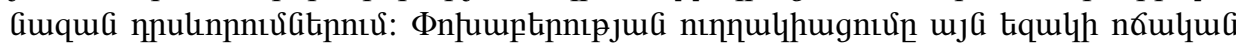

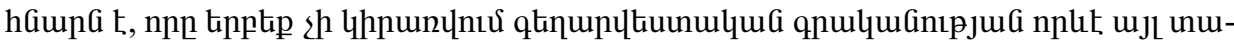

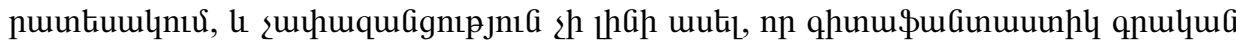

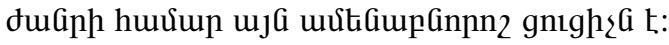

